\title{
Effect of social deprivation on disease severity and outcome in patients with rheumatoid arthritis
}

\author{
A McEntegart, E Morrison, H A Capell, M R Duncan, D Porter, R Madhok, \\ E A Thomson
}

\begin{abstract}
Objective-Social deprivation is now recognised to have an important impact on morbidity and mortality. This study sought to ascertain the effect of deprivation, if any, on disease severity, functional disability, and outcome in rheumatoid patients in Glasgow.

Methods-814 patients with rheumatoid arthritis (RA) were assessed for clinical, functional, and laboratory indices of disease activity. Deprivation categories for individual patients were determined using the Carstairs index. Five year follow up is available for 440 patients.

Results-The study population of RA patients live largely in the most deprived areas. Patients from deprived areas have significantly poorer function at outset and at five years as defined by the Health Assessment Questionnaire (HAQ) score. This is not attributable to differences in disease duration in patients from the most deprived regions or compliance with treatment. Furthermore, these patients do not achieve over five years the initial functional level of those living in the most advantaged localities.

Conclusion-RA patients from deprived areas have poorer function, which is associated with greater need-medical, social, and paramedical. Strategies and resources for healthcare need to be adjusted according to this variation.
\end{abstract}

(Ann Rheum Dis 1997;56:410-413)

The effect of socioeconomic disadvantage on mortality patterns is well documented and has important implications for health care strategies. ${ }^{12}$ The effect of deprivation on the course and outcome of a chronic disease such as rheumatoid arthritis (RA) may also be important and may influence patient welfare over many years or indeed decades. Formal education may be regarded as a surrogate

Table 1 Percentage of patients in each deprivation category compared with the population in the west of Scotland, Scotland as a whole, and England and Wales

\begin{tabular}{|c|c|c|c|c|c|c|c|c|}
\hline & \multicolumn{8}{|c|}{ Deprivation category } \\
\hline & \multicolumn{5}{|c|}{ Most affluent } & \multicolumn{2}{|c|}{ Most deprived } & \multirow{2}{*}{$\begin{array}{l}\text { Missing } \\
\text { postcode }\end{array}$} \\
\hline & 1 & 2 & 3 & 4 & 5 & 6 & 7 & \\
\hline 440 patients started on im gold (\%) (1980s) & 5.7 & 5.2 & 10.5 & 20 & 16.4 & 21.8 & 15.2 & 5.2 \\
\hline 374 patients started on sulphasalazine (1990s) & 5.6 & 5.9 & 10.9 & 19.7 & 10.4 & 22.4 & 16.3 & 8.8 \\
\hline W Scotland population (\%) & 8 & 10 & 18 & 20 & 17 & 17 & 10 & \\
\hline Scotland & 6 & 14 & 22 & 25 & 15 & 11 & 7 & \\
\hline England and Wales (\%) & 21.6 & 30.4 & 21.7 & 14.7 & 7.6 & 3.6 & 1.0 & \\
\hline
\end{tabular}

marker of socioeconomic status although there are many confounding factors. Pincus et al have shown that outcome of RA in terms of laboratory and functional measurements of disease activity is inversely related to the number of years of formal education in the USA. ${ }^{3}$ The cause of this relation is unclear and cannot be explained by age or disease duration. Glasgow has side by side extremes of affluent and impoverished groupings ${ }^{4}$ with documented effects on mortality. Standardised death ratios vary in Glasgow from 71 (95\% confidence intervals ((CI) 67, 76) for the most affluent to 159 (CI 155, 164) for the most deprived. $^{5}$

In this study we assessed the social deprivation profile of RA patients attending a hospital based outpatient department. This was compared with the population served in the west of Scotland, the general population in Scotland, and those in England and Wales. Furthermore, we wished to ascertain the effect, if any, of deprivation on disease severity, functional disability, disease outcome, and the likelihood of continuing to need disease modifying treatment.

\section{Methods}

PATIENTS

The study population consisted of 814 RA patients attending two specialist clinics. Patients with active synovitis and with either prolonged morning stiffness or an acute phase response or both were enrolled in two prospective studies of second line therapy: (1) intramuscular gold (recruited 1986-1989, $\mathrm{n}=440$ with five year follow up available on these patients); (2) sulphasalazine (recruited between 1990-1993, $\mathrm{n}=374$ )

Patients considered unlikely to comply with monitoring or who had developed a side effect or had no response to that second line drug previously were excluded from these studies. Demography, disease duration, and clinical severity were recorded in both RA cohorts. and laboratory indices of disease activity and

H A Capell

R Madhok

E A Thompson

Gartnavel General Hospital, Glasgow M R Duncan

D Porter

Correspondence to: Dr A McEntegart, Centre for Rheumatic Disease, Glasgow Royal Infirmary, 84 Castle Street, Glasgow G4 OSF.

Accepted for publication 22 April 1997

Centre for Rheumatic Disease, Glasgow Glasgow A McEntegart 
Table 2 Demographic features and indices of disease activity in two cohorts of $R A$ patients (medians and range at outset are shown)

\begin{tabular}{|c|c|c|c|c|c|c|c|c|}
\hline \multirow[b]{2}{*}{ Deprivation category } & \multicolumn{4}{|c|}{ Gold cohort 1980 s $(n=440)$} & \multicolumn{4}{|c|}{ Sulphasalazine cohort 1990-1993 $(n=374)$} \\
\hline & 1 and 2 & 3,4 and 5 & 6 and 7 & Kruskal-Wallis & 1 and 2 & 3,4 and 5 & 6 and 7 & Kruskal-Wallis \\
\hline Age (y) & $58(21-80)$ & $57(26-86)$ & $58(19-81)$ & 0.73 & $60(28-80)$ & $60(27-80)$ & $60(21-87)$ & 0.89 \\
\hline Disease duration (y) & $4(1-35)$ & $7(1-89)$ & $6.6(1-40)$ & 0.29 & $6(1-42)$ & $8(1-40)$ & $7(1-45)$ & 0.90 \\
\hline Weight $(\mathrm{kg})$ & $55(41-99)$ & $62(21-99)$ & $61(32-99)$ & $\mathrm{p}<0.001$ & - & - & - & - \\
\hline Pain score & $1.8(0.4-2.8)$ & $2.0(0.3-3)$ & $1.9(0.7-3)$ & 0.50 & $3(1-4)$ & $3(0-4)$ & $3(1-4)$ & 0.93 \\
\hline Morning stiffness (min) & $60(0-720)$ & $120(0-720)$ & $120(0-720)$ & $\mathrm{p}<0.05$ & $90(0-720)$ & $60(0-720)$ & $60(0-720)$ & 0.92 \\
\hline Articular index & $12(0-29)$ & $13(0-39)$ & $14(0-42)$ & 0.17 & NA & NA & NA & - \\
\hline $\operatorname{ESR}(\mathrm{mm} \mathrm{1st} \mathrm{h)}$ & $57(11-150)$ & $58(2-124)$ & $52(0-150)$ & 0.66 & $54(15-150)$ & $50(2-131)$ & $41(0-150)$ & 0.11 \\
\hline $\mathrm{CRP}(\mathrm{mg} / \mathrm{l})$ & $37(3-256)$ & $41(4-255)$ & $34(6-255)$ & 0.70 & $31(3-143)$ & $27(3-233)$ & $26(4-212)$ & 0.53 \\
\hline HAQ & $1.75(0.4-2.88)$ & $2.0(0-3)$ & $2.0(0.12-3)$ & $\mathrm{p}<0.05$ & $1.62(0-2.88)$ & $1.88(0.12-3)$ & $2.12(0-3)$ & $\mathrm{p}=0.09$ \\
\hline
\end{tabular}

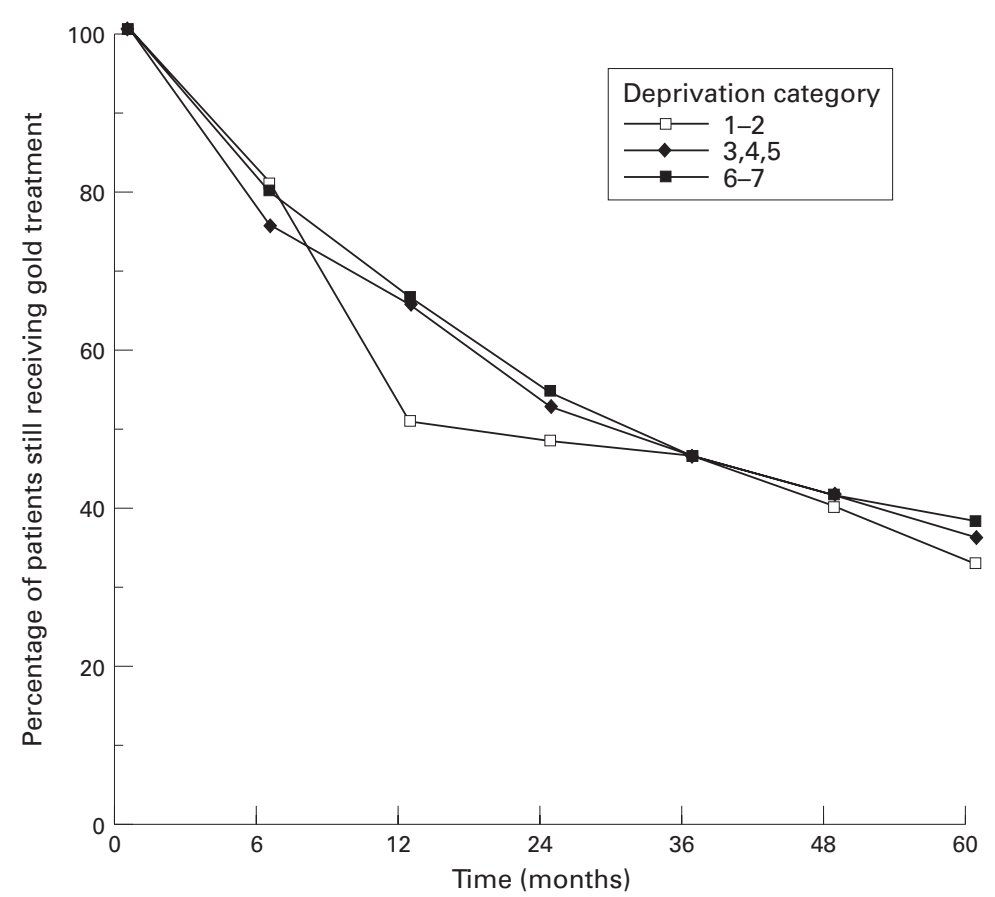

Figure 1 Percentage of patients still receiving gold treatment split for deprivation categories. already been recruited by that time. Clinical, functional, and laboratory data were analysed by grouping together deprivation categories 1 and 2, 3, 4, and 5, and 6 and 7 . Non-parametric statistical analysis using the Kruskal-Wallis test was performed across the three groups.

\section{Results}

Table 1 shows the percentage of patients in each deprivation category compared with the population in the west of Scotland, Scotland as a whole, and in England and Wales. A total of $8.8 \%$ of patients in the sulphasalazine and $5.2 \%$ in the gold group could not be categorised. The proportion of RA patients in the most and least affluent groups is similar in the cohorts recruited in the $1980 \mathrm{~s}$ and the 1990s. These RA patients live in more deprived areas and are substantially more deprived than the population in Scotland as a whole and that in England and Wales.

Table 2 shows the demographic and clinical parameters for the two RA cohorts at outset. The 1990s cohort tended to have slightly milder disease. Age, disease duration, and disease activity did not differ significantly across the three Carstairs groupings (that is, 1 and 2, 3, 4, and 5, 6 and 7). However, significantly poorer functional status was seen in patients in more deprived areas (Kruskal-Wallis). In the gold group the median HAQ was 1.75 in the most affluent and 2 in the most deprived; and in the sulphasalazine cohort the values were 1.625 and 2.125 respectively. Initial weights were available in the gold cohort and showed, as might be expected, significantly higher median weight in the more disadvantaged patients.

Five year follow up data in the gold group showed that at five years $35 \%$ of the 440 gold patients were still receiving treatment, $40 \%$ had discontinued treatment because of side effects, and a further $11 \%$ because of lack of efficacy. In addition $6 \%$ had stopped treatment because of lack of compliance or intercurrent illness. Fifty six (13\%) had died of problems unrelated to treatment (table 3). Figure 1 shows the percentage of patients receiving injectable gold over the five year period in the three deprivation categories. It can be seen that the likelihood of remaining on treatment is similar in all three groups.

Table 4 shows the paired year 0 and year 5 data for those remaining on gold treatment. It can be seen that significant within group improvements occurred for all measurements were obtained from 1981 census data. This was considered to be more relevant than the 1991 census as the majority of RA patients had 
Table 3 Number of deaths over five years in the gold cohort split for deprivation categories (medians and range are shown)

\begin{tabular}{lccc}
\hline \multicolumn{3}{l}{ Deprivation category } \\
\cline { 2 - 4 } & 1 and 2 & 3,4 , and 5 & 6 and 7 \\
\hline Age (y) & $58(21-80)$ & $57(26-86)$ & $58(19-81)$ \\
HAQ (at outset) & $1.75(0.4-2.88)$ & $2.0(0-3)$ & $2.0(0.12-3)$ \\
Deaths & 6 & 31 & 16 \\
Expected no of deaths & 6 & 26 & 12 \\
\hline
\end{tabular}

(Wilcoxon matched pairs signed ranks test). The HAQ score improves in all groups with treatment. However those patients from more deprived areas - that is, Carstairs groups 3, 4, and 5 , and 6 and 7 did not achieve at five years the median functional ability that the most affluent had enjoyed at the beginning.

\section{Discussion}

Our results show that functional status is significantly worse in RA patients from the most deprived areas at enrolment to the gold and sulphasalazine studies. Pincus and colleagues found $\mathrm{HAQ}$ to be the most representative of all variables measured in depicting the clinical status in an RA patient. ${ }^{8}$ In addition it is predictive of morbidity and death rates over 5-10 years. Thus those patients with poor HAQ at outset can be expected to have a worse prognosis in terms of disease outcome. As the patients with most severe disease and deprivation are more likely to have died over the five years the results obtained are almost certainly a conservative estimate of the extent of the problem.

There were minor although non-significant differences in disease duration between the three groups of patients in both the sulphasalazine and gold cohorts. In the sulpasalazine cohort the patients with longest disease duration (deprivation categories 3, 4, and 5) do not have the poorest function. Thus disease duration does not fully explain the differences in the HAQ scores. Our data and work by Vliet Vieland $e t a l^{9}$ argue against a longer delay in the most deprived to first consultation with a rheumatologist. It is possible however that patients from more deprived areas only consult their general practitioner when they have severe disease whereas those in more affluent neighbourhoods may consult a doctor with milder symptoms. There may also be differences in perception of onset of disease according to educational level. Access to health care is also an important factor, and will vary between social groups. In an American study ${ }^{10}$ higher educational groups were more likely to be hospitalised or undergo surgery for RA. This sug- gests that more educated people are 'better equipped to negotiate for medical care' and not that they are necessarily more 'needy'. Our data suggest a trend towards worse disease activity in patients from more deprived areas (categories 6 and 7). This has been shown in previous studies and may indicate that more deprived patients have worse RA. ${ }^{38}$ Furthermore, after five years of gold treatment inequalities in HAQ score persisted with the most deprived patients not achieving over five years the initial functional level of those from the most affluent areas. At present provision of funding in rheumatology and allocation of resources is based on the assumption that the risk of disease and responses to treatment are equal in all people at a given age and sex. Our results would suggest that this is not the case. The most deprived patients have the most severe disease, worse functional outcome, and consequently require more resources. Indeed, it has been shown that caring for the poor costs more in the United States. ${ }^{11}$

The poorer functional outcome that we have observed in RA patients from more deprived locations is almost certainly multifactorial. The relative contributions of comorbidity, in particular other chronic diseases and of smoking might well be relevant. It has been shown that smoking is associated with more severe disease but it is also true that deprived groups are more likely to smoke. In addition, dietary factors, the association of overcrowding with infection, and lack of formal education are likely to be important. While the development of RA may in itself contribute to relegating the person to a less affluent Carstairs category because of loss of employment and earning capacity, a study in the south of England at outset of RA suggests that this effect is apparent at onset of disease. ${ }^{12}$

The extent of the problem in our population of RA patients is striking for their functional status is considerably worse than that reported elsewhere in Western Europe and in North America. ${ }^{13}$ It is ironic that the factors that are associated with poor outcome are in themselves likely to perpetuate disadvantage (that is, lack of access to a car, overcrowded accommodation with lack of privacy and inadequate space for modifications of the home environment).

As the HAQ score has been shown to have an effect on outcome, both in terms of morbidity and mortality, the findings from this study are highly relevant.

Patients from deprived areas have poorer function, which is associated with greater

Table 4 Changes in clinical and laboratory features over five years for patients remaining on gold (medians and range are shown)

\begin{tabular}{|c|c|c|c|c|c|c|}
\hline & \multicolumn{6}{|c|}{ Deprivation category } \\
\hline & \multicolumn{2}{|l|}{1 and 2} & \multicolumn{2}{|l|}{3,4 , and 5} & \multicolumn{2}{|l|}{6 and 7} \\
\hline & 0 & Five years & 0 & Five years & 0 & Five years \\
\hline Pain score & $1.8(0.4-2.8)$ & $0.9(0-2.5)$ & $2.0(0.3-3)$ & $1.5(0-3)$ & $1.9(0.7-3)$ & $1.5(0-4.5)$ \\
\hline Morning stiffness ( $\mathrm{min}$ ) & $60(0-720)$ & $20(0-360)$ & $120(0-720)$ & $30(0-720)$ & $120(0-720)$ & $60(0-720)$ \\
\hline Articular index & $12(0-29)$ & $3(0-20)$ & $13(0-39)$ & $4(0-23)$ & $14(0-42)$ & $4(0-29)$ \\
\hline $\operatorname{ESR}(\mathrm{mm} 1 \mathrm{st} \mathrm{h})$ & $57(11-150)$ & $12(0-85)$ & $58(2-124)$ & $18(2-150)$ & $52(0-150)$ & $23(1-100)$ \\
\hline CRP (mg/l) & $37(3-256)$ & $10(3-130)$ & $41(4-255)$ & $12(3-119)$ & $34(6-255)$ & $12(3-138)$ \\
\hline HAQ & $1.8(0.4-2.88)$ & $1.12(0-2.75)$ & $2.0(0-3)$ & $1.81(0-3)$ & $2.0(0.12-3)$ & $1.88(0-3)$ \\
\hline
\end{tabular}


need-medical, social, and paramedical. It is therefore essential that this is recognised and strategies for healthcare planned accordingly.

We would like to thank Mrs D McKnight for computing assistance and Miss A Tierney for secretarial help. Mr D Hole of the Cancer Surveillance Unit kindly provided statistical advice.

1 Hinkle LE, Whitney LH, Lehman EW, Dunn J, Benjamin B, King R, et al. Occupation, education and coronary hear disease. Science 1968;161:238-46.

2 Marmot MG, McDowall ME. Mortality decline and widening social inequalities. Lancet 1986;ii:274-6.

3 Callahan LF, Pincus T. Formal education level as a significant marker of clinical status in rheumatoid arthritis. Arthritis Rheum 1988;31:1346-57.

4 McCarron PG, Davey Smith G, Womersley JJ. Deprivation and mortality in Glasgow: changes from 1980 to 1992 BMJ 1994;309:1481-2.

5 McLoone P, Boddy FA. Deprivation and mortality in Scotland, 1981 and 1991. BMJ 1994;309:1465-70.

6 Fries JF, Spitz PW, Kraines RG, Holman HR. Measuremen of patient outcome in arthritis. Arthritis Rheum 1980 23:137-45.
7 Carstairs V, Morris R. Deprivation and health in Scotland. Aberdeen: Aberdeen University Press, 1991.

8 Pincus T, Callahan LF, Vaughn WK. Questionnaire, walking time and button test measures of functional capacity as predictive markers for mortality in rheumatoid arthritis. J Rheumatol 1987;14:240-51.

9 Vliet Vlieland TPM, Buitenhuis NA, Breedveld FC, Hazes JMW. Sociodemographic factors and the outcome of rheu-
matoid arthritis in young women. Ann Rheum Dis matoid arthritis

10 Criswell LA, Katz PP. Relationship of education level to treatment received for rheumatoid arthritis. J Rheumatol 1994;21:2026-33.

11 Epstein AM, Stern RS, Weissman JS. Do the poor cost more? A multihospital study of patients' socio-economic status and use of hospital resources. N Engl J Med status and use

12 Talamo J, Wilkinson P, Cox N, Davis P, Devlin J, Dixey J, et al. Socio-economic factors in rheumatoid arthritis: the effect on functional outcome at three years in 516 patients. [Abstract]. Br J Rheumatol 1996;35 (suppl 1):234

13 Weinblatt ME, Kaplan H, Germain BF, Block S, Solomon $\mathrm{SD}$, Merriman RC, et al. Methotrexate in rheumatoid arthritis. a five-year prospective multicentre study. Arthritis Rheum 1994;37:1492-8. 